\title{
A "Unisex" Occupational Scale for the Strong-Campbell Interest Inventory
}

\author{
Richard W. Johnson \\ University of Wisconsin at Madison
}

Previous research has shown that the female Pharmacist scale on the Strong-Campbell Interest Inventory (SCII) was more valid than the male Pharmacist scale for both male and female college students. The female scale was not as valid for men as it was for women, however, because of the sex differences reflected in its item content. In an attempt to develop a "unisex" occupational scale which would be equally effective for men and women, all items which differentiated between males and females by 10 percentage points or more were eliminated from the female scale. The remaining items ( 20 of 39 original items) formed a short unisex scale that was nearly as reliable and valid as the original scale over short time periods. The unisex version did not require separate norms or different interpretations of the scores for men and women. The possibility of constructing an abbreviated form of the SCII that contains only sex-balanced items merits further consideration.

Despite attempts to remove sexual bias from the Strong-Campbell Interest Inventory (SCII), separate occupational scales for men and women have been preserved (Campbell, 1977). Separate scales are necessary to take into account the sex differences associated with the SCII items. Approximately one-half of the 325 items on the SCII differentiate between menand women-in-general by at least 15 percentage points or more (Campbell, 1977, p. 69).

APPLIED PSYCHOLOGICAL MEASUREMENT Vol. 2, No. 4 Fall 1978 pp. 527-532

(c) Copyright 1978 West Publishing Co.
Combined occupational scales may be feasible if the items which show large sex differences are eliminated from the scales (Hanson, Prediger, \& Schussel, 1977; Hanson \& Rayman, 1976; Rayman, 1976). This procedure would shorten each of the scales considerably; however, the effort may prove to be worthwhile if the abbreviated scales retain most of their reliability and validity. Short forms of the Minnesota Multiphasic Personality Inventory have suffered relatively little loss in reliability and validity compared with the standard form (Kincannon, 1968; Freeman, O'Leary, \& Calsyn, 1977).

The purpose of this study was to investigate the feasibility of constructing a brief "unisex" occupational scale for the SCII that could be used effectively with both men and women. Specifically, the possibility of developing a unisex occupational scale for pharmacists was explored.

\section{Method}

\section{Scale Development}

At the present time, there are two Pharmacist scales, one for men and one for women, on the SCII profile. The scores on these two scales are only moderately correlated $(r=.46$ to .58 ; Campbell, 1977, p. 74). The male scale reflects business interests, while the female scale emphasizes scientific interests. 
In two recent studies, the female Pharmacist scale proved to be more valid than the male Pharmacist scale for both females and males (Johnson, Kirk, \& Ohvall, 1975; Johnson, Kirk, Ohvall, \& Barbre, 1978). The male pharmacy students in these studies, drawn from three universities, had stronger scientific than business interests. Although the female Pharmacist scale was more valid than the male Pharmacist scale for both sexes, it did not differentiate between the interests of male pharmacy and non-pharmacy students as well as it did between female pharmacy and non-pharmacy students (Johnson et al., 1978).

The female scale was not as valid for men as it was for women because of the use of items that showed large sex differences in constructing the scale (Johnson, 1977; Lunneborg, 1975). According to the scale construction procedures, only those items that differentiate men and women in an occupation from men- or women-in-general appear on an occupational scale. For example, the items "Jet pilot" (Like) and "Dramatics" (Dislike) are scored on the female scale because these items differentiate between the interests of women pharmacists and women-in-general. These items are not scored on the male scale because they do not differentiate between the interests of men pharmacists and men-in-general. Such interests, which reflect cultural expectations, are unusual for women but relatively common for men.

When a male is scored on the female Pharmacist scale, his scores will be artificially high. Men consistently score approximately five standard scores higher on the female scale than do women (Campbell, 1977, p. 55; Creaser \& Carsello, 1976; Johnson et al., 1978). Because of the inflated scores for men on the women's Pharmacist scale, the scale is less helpful than it might be in identifying male students who may wish to pursue pharmacy as a career.

In order to eliminate the sex differences inherent in the scale, the women's scale was refined by deleting all of the items that differentiated between male and female college fresh- men by 10 percentage points or more (Johnson, 1974). Nineteen of the 39 items on the women's scale were dropped by this process. Items such as "Jet pilot" and "Dramatics" were culled. The remaining 20 items (e.g., "Laboratory technician" and "Watching an open-heart operation") were preferred equally by men and women.

\section{Statistical Analysis}

The test-retest reliability of the unisex scale was compared with that of the male and female scales for both a 30-day interval and a 3-year interval. The concurrent validity of the unisex scale was evaluated by means of Tilton's (1937) overlap percentage. This measure was used to determine the relative effectiveness of the three Pharmacist scales in differentiating between pharmacy students and non-pharmacy students.

\section{Subjects}

Descriptions of the samples used in the two reliability studies may be found in the SCII Manual (Campbell, 1977, p. 34). The 30-day sample consisted of 102 men and women drawn from diverse sources; the 3-year sample included 140 employed men and women between the ages of 25 and 55.

Students enrolled in Schools of Pharmacy at three universities and a cross-section of nonpharmacy students at one of the three universities were used as subjects in determining the concurrent validity of each scale (Johnson et al., 1978). The data for the three pharmacy schools were combined after it was determined that the mean scores of male and female students at the different schools were relatively similar. A total of $89 \%$ of the male students (346 of 389$)$ and $91 \%$ of the female students (140 of 154) at the three schools provided usable answer sheets. The non-pharmacy students consisted of the first 150 male students and 150 female students who completed the SCII as part of their counseling program at the University of Wisconsin-Madison after the SCII was introduced in July 1974. 


\section{Results}

The test-retest reliabilities for each of the scales are presented in Table 1 . The reliability of the unisex scale $(r=.82)$ compared favorably with the reliabilities of the male scale $(r=.80)$ and the female scale $(r=.87)$ for the 30-day sample. The reliability of the unisex scale $(r=.71)$ was appreciably less than the reliability of the female scale $(r=.82)$ and the male scale $(r=.78)$ for the 3-year sample. Scores on the short unisex scale may be expected to change more than scores on the full-length female or male scales over long time periods. The loss in reliability for the unisex scale compared with the female scale is about what would be expected by taking into account the reduction in the number of items by means of the Spearman-Brown prophecy formula (McNemar, 1969).
The relative effectiveness of the Pharmacist scales in differentiating between the interests of pharmacy students and non-pharmacy students is shown in Table 2 . The male scale was least effective in distinguishing between the two groups for both female students ( $50 \%$ overlap) and male students ( $42 \%$ overlap). The female scale differentiated between pharmacy and non-pharmacy students slightly better than the unisex scale for both females (34\% overlap versus $39 \%$ overlap) and males (36\% overlap versus $38 \%$ overlap). Contrary to previous research, the female Pharmacist scale was nearly as valid for men as it was for women, apparently because the interests of the general reference samples of men and women (all Counseling Service clients) did not differ as much as they had in other studies. The unisex scale was not as valid as the female scale for either sex; however, the loss of validity

Table 1

Test-Retest Reliability of SCII Pharmacist Scales

\begin{tabular}{|c|c|c|c|c|c|}
\hline \multirow{2}{*}{$\begin{array}{l}\text { SCII Pharmacist } \\
\text { scale }\end{array}$} & \multicolumn{2}{|c|}{ Test } & \multicolumn{2}{|c|}{ Retest } & \multirow{2}{*}{$\underline{r}$} \\
\hline & Mean & $\underline{\mathrm{SD}}$ & Mean & $\underline{\mathrm{SD}}$ & \\
\hline \multicolumn{6}{|c|}{ 30-day sample $\quad(\underline{\mathrm{n}}=102)$} \\
\hline $\begin{array}{l}\text { Female scale } \\
\text { Male scale } \\
\text { Unisex scale }\end{array}$ & $\begin{array}{l}30 \\
29 \\
-2.47\end{array}$ & $\begin{array}{r}13.0 \\
10.7 \\
6.30\end{array}$ & $\begin{array}{l}31 \\
29 \\
-2.29\end{array}$ & $\begin{array}{l}12.7 \\
11.9 \\
6.14\end{array}$ & $\begin{array}{l}.87 \\
.80 \\
.82\end{array}$ \\
\hline \multicolumn{6}{|c|}{ 3-year sample $\quad(\underline{\mathrm{n}}=140)$} \\
\hline $\begin{array}{l}\text { Female scale } \\
\text { Male scale } \\
\text { Unisex scale }\end{array}$ & $\begin{array}{c}33 \\
27 \\
-1.63\end{array}$ & $\begin{array}{r}12.6 \\
11.2 \\
5.87\end{array}$ & $\begin{array}{c}33 \\
26 \\
-1.65\end{array}$ & $\begin{array}{l}13.2 \\
12.4 \\
6.43\end{array}$ & $\begin{array}{l}.82 \\
.78 \\
.71\end{array}$ \\
\hline
\end{tabular}

Note. Data provided by Jo-Ida Hansen, Director, Center for Interest Measurement Research, University of Minnesota.

${ }_{\text {Raw }}$ scores based on item weights of $-1,0$, and +1 were used as described by Campbell (1977, pp. 49-50). 
Table 2

Concurrent Validity of SCII Pharmacist Scales

\begin{tabular}{|c|c|c|c|c|c|}
\hline \multirow{2}{*}{$\begin{array}{c}\text { SCII Pharmacist } \\
\text { scale }\end{array}$} & \multicolumn{2}{|c|}{$\begin{array}{c}\text { College students- } \\
\text { in-general }\end{array}$} & \multicolumn{2}{|c|}{$\begin{array}{l}\text { Pharmacy } \\
\text { students }\end{array}$} & \multirow{2}{*}{$\begin{array}{l}\text { Percent } \\
\text { overlap }\end{array}$} \\
\hline & Mean & $\underline{S D}$ & Mean & SD & \\
\hline
\end{tabular}

Female students

\begin{tabular}{llcccc}
\hline Female scale & 27.9 & 12.0 & 47.7 & 9.0 & $34 \%$ \\
Male scale a & 24.4 & 11.7 & 39.5 & 10.7 & $50 \%$ \\
Unisex scale & -2.39 & 6.43 & 7.26 & 4.82 & $39 \%$ \\
\hline
\end{tabular}

Male students

\begin{tabular}{llcccc}
\hline Female scale & 30.6 & 11.4 & 49.3 & 9.1 & $36 \%$ \\
Male scale & 23.8 & 12.1 & 42.5 & 11.4 & $42 \%$ \\
Unisex scale & -3.10 & 5.91 & 6.40 & 4.89 & $38 \%$ \\
\hline
\end{tabular}

Note. $\underline{n}=150$ female college students-in-general, 140 female pharmacy students, 150 male college students-in-general, 346 male pharmacy students.

${ }^{a}$ Raw scores based on $i$ tem weights of $-1,0$, and +1 were used as described by Campbel1 (1977, pp. 49-50).

was relatively small. The unisex scale produced equivalent results for men and women.

Similar mean scores on the unisex Pharmacist scale were obtained for men and women nonpharmacy students, $z(298)=1.00 ; p>.05$, and for men and women pharmacy students, $z$ (484) $=1.77 ; p>.05$. The same norms may be used with both sexes.

As expected, the mean scores on the separate sex scales differed significantly for some of the comparisons between the male and female groups. The male college students scored significantly higher on the female Pharmacist scale than did the female students, $z(298)=2.00 ; p<$ .05 , although the difference was not as great as that obtained in previous studies. The male pharmacy students scored significantly higher on the male Pharmacist scale than did the fe- male pharmacy students, $z(484)=2.75 ; p<.01$. Separate sex norms should be used for the separate sex scales.

The intercorrelations of scores on the three scales for the samples of male and female college students may be noted in Table 3. Scores on the male and female Pharmacist scales were moderately intercorrelated for men $(r=.60)$ and women $(r=.53)$, as suggested by Campbell's (1977) research. Similar correlations were obtained between the unisex scale and male scale. Scores on the unisex scale, an abridged version of the female scale, were highly correlated with scores on the female scale for men $(r=.90)$ and women $(r=.91)$. The unisex and the female scales should produce comparable results in most situations. 
Table 3

Intercorrelations of SCII Pharmacist Scales

\begin{tabular}{lccc}
\hline & $\begin{array}{c}\text { Female } \\
\text { scale }\end{array}$ & $\begin{array}{c}\text { Male } \\
\text { scale }\end{array}$ & $\begin{array}{r}\text { Unisex } \\
\text { scale }\end{array}$ \\
\cline { 2 - 3 } & -- & .53 & .91 \\
Female scale & .60 & .57 & .62 \\
Male scale & .90 & .57 & -- \\
Unisex scale & & & \\
\hline
\end{tabular}

Note. Correlations above the diagonal are for female college students-in-general $(\underline{n}=150)$. Correlations below the diagonal are for male college students-in-general $(\underline{n}=150)$.

\section{Discussion and Conclusions}

Sex bias appears to have been successfully avoided in the unisex Pharmacist scale. The same norms may be used for both men and women. The scale appears to be equally valid for men and women so that the same interpretations may be used for both sexes.

This study supports the research by Hansen (1976) and Webber and Harmon (1974) with other SCII occu pational scales. In these studies, abbreviated unisex scales based upon sex-balanced items were nearly as valid as the traditional scales.

The unisex Pharmacist scale falls short of the standard set by the female scale in terms of its long-term test-retest reliability. The unisex scale probably would not perform as well in longitudinal validity studies as the female scale. Additional sex-balanced items would have to be added to the item pool to correct for this deficiency.

It may be worthwhile to develop a shorter version of the SCII that contains only sex-balanced items. Such a form could be constructed based upon data that already have been collected. A sex-balanced version of the SCII would prove to be more acceptable to many clients and should produce results that are easier to interpret than the present form. A shorter version of the SCII may also prove to be advantageous for those cases in which time is limited. In many instances, a short form may provide a sufficient measure of interests if the results are to be used for exploratory counseling or for research purposes.

\section{References}

Campbell, D. P. Manual for the Strong-Campbell Interest Inventory (2nd ed.). Stanford, CA.: Stanford University Press, 1977.

Creaser, J., \& Carsello, C. Comparability of cross-sex scores in the Strong-Campbell Interest Inventory. Journal of Counseling Psychology, 1976, 23, 360-364.

Freeman, C. W., O'Leary, M. R., \& Calsyn, D. Application of the Faschingbauer Abbreviated MMPI with alcoholic patients. Journal of Clinical Psychology, 1977, 33, 303-306.

Hansen, J. C. Exploring new directions for StrongCampbell Interest Inventory occupational scale construction. Journal of Vocational Behavior, 1976, 9, 147-160.

Hanson, G. R., Prediger, D. J., \& Schussel, R. H. Development and validation of sex-balanced interest inventory scales (ACT Research Report No. 78). Iowa City, IA: American College Testing Program, March 1977. 
Hanson, G. R., \& Rayman, J. Validity of sex-balanced interest inventory scales. Journal of Vocational Behavior, 1976, 9, 279-291.

Johnson, R. W. Comparison of item responses of college men and women on Strong-Campbell Interest Inventory. Paper presented at Annual Convention of American College Personnel Association, Chicago, April 1974.

Johnson, R. W. Relationships between female and male interest scales for the same occupations. Journal of Vocational Behavior, 1977, 11, 239-252.

Johnson, R. W., Kirk, K. W., \& Ohvall, R. A. Predictive validity of SVIB Pharmacist scales. Educational and Psychological Measurement, 1975, 35. 951-955.

Johnson, R. W., Kirk, K. W., Ohvall, R. A., \& Barbre, A. R. Use of the Strong-Campbell Interest Inventory with female and male pharmacy students. Measurement and Evaluation in Guidance, 1978, $11,99-105$.

Kincannon, J. C. Prediction of the standard MMPI scale scores from 71 items: The Mini-Mult. Journal of Consulting and Clinical Psychology, 1968, 32. 319-325.

Lunneborg, P. W. Interpreting other-sex scores on the Strong-Campbell Interest Inventory. Journal of Counseling Psychology, 1975, 22, 494-499.

McNemar, Q. Psychological statistics (4th ed.). New York: Wiley, 1969.

Rayman, J. R. Sex and the single interest inventory: The empirical validation of sex-balanced interest inventory items. Journal of Counseling Psychology, 1976, 23, 239-246.

Tilton, J. W. The measurement of overlapping. Journal of Educational Psychology, 1937, 28, 656-662.

Webber, P. L., \& Harmon, L. W. A concurrent validity study of single-sex and combined-sex scales. Paper presented at the Annual Convention of the American Personnel and Guidance Association, New Orleans, April 1974.

\section{Acknowledgements}

The assistance of Kenneth W. Kirk, Richard A. Ohvall, and Ann Rouege Barbre in obtaining the data for pharmacy students analyzed in this article is gratefully acknowledged. The samples and data analysis for the test-retest reliability phase were provided by Jo-Ida Hansen of the Center for Interest Measurement Research, University of Minnesota. A preliminary version of this paper was presented at the Annual Convention of the American Personnel and Guidance Association, Dallas, TX, March 1977.

\section{Author's Address}

Richard W. Johnson, Counseling Service, University of Wisconsin at Madison, 432 N. Murray St., Madison, WI 53706. 